\title{
Optimization of Process Parameters to Achieve Nano Level Surface Quality on Polycarbonate
}

\author{
Neha Khatri \\ CSIR-Central Scientific \\ Instruments Organisation \\ Chandigarh \\ India, 160030
}

\author{
Vinod Mishra \\ CSIR-Central Scientific \\ Instruments Organisation \\ Chandigarh \\ India, 160030
}

\author{
Rama Gopal V Sarepaka \\ CSIR-Central Scientific \\ Instruments Organisation \\ Chandigarh \\ India, 160030
}

\begin{abstract}
Optical grade plastics are increasingly being used as magnifiers in Ophthalmic Optical Instrumentation applications. In its effort to develop indigenously aspheric technology-based Ophthalmic Optical aids, the Aspheric Group at CSIO has studied the machining and surface characteristics of optical grade plastics. Generally, PMMA and polycarbonate considered as suitable candidates for aspheric Visual aids. In the study presented, optical grade polycarbonate is explored for its single-point diamond turning (SPDT) features and its profile characteristics. This study focuses on the optimization of SPDT machining parameters viz: tool feed rate, depth of cut, spindle speed for a given tool nose radius. In this study, the machining sensitivity in terms of surface roughness and profile error $(\mathrm{Pt})$ is investigated. It is found that machining parameters play a major role in surface quality optimization in terms of roughness and profile. Based on optimized machining parameters, good quality aspheric lens is developed.
\end{abstract}

\section{Keywords}

Single point diamond turning (SPDT), Surface roughness, Profile error, machining parameters and tool path

\section{INTRODUCTION}

Single-point diamond turning (SPDT) is an ultra-precision machining technique which is used to produce optical surfaces (spherical and aspheric) of submicron form accuracy and surface finish in the nano-metric range. The diamond turning machine is sophisticated equipment, which produces the final surface, without the need of traditional polishing operation. SPDT is being used with increasing frequency to fabricate precision elements, especially unconventional surfaces. SPDT can used to process many non-ferrous metals, IR materials, and plastics [1]. The advantages of using diamond turning, includes the ability to produce good optical surfaces to the edge of the element, to fabricate soft ductile materials difficult to polish, to eliminate alignment in some systems, and to fabricate shapes difficult to do by other methods [2]. The diamond turning is widely used to fabricate high precision surfaces-from crystals, metals, acrylic, and other materials. The mechanism of surface generation differs from that of conventional machining. The need of high quality and nano scale surface finish necessitates use of micro-machining. It is impossible to achieve similar surface quality by conventional machining methods. SPDT has long played an important role in the field of optics. In recent decades SPDT has attracted much attention of researchers of this field owing to their advantages over traditional methods. The Objective of this work includes investigating the effects of machining parameters: e.g. Spindle Speed, Feed rate and Depth of cut on surface quality and tool path optimization for aspheric surfaces to achieve minimum profile error.

SPDT is a complex process. It is an interactive process which may require several iterations before the best result is achieved. When unusual and complex products are to be developed by SPDT, the system developer generally relies on the experience and skills of operator. Every new product development demands vast resources in terms of money, men and time. Diamond turning of plastics is more complicated than metals due to the thermal behavior of plastics. Recently, in optical instrumentation, polycarbonate materials are fast replacing glass due to their properties like: light weight, dimensional integrity, procesasbility, thermal stability during varying environmental conditions [3], processing costs etc.

Since surface roughness affects the performance of the lens, one needs to generate finely machined surface with minimum roughness. Casual selection of combination of machining parameters may affect the surface quality, so it is required to optimize the machining parameters before final SPDT process. Machining of aspheric surface is more complicated than spherical and flat surfaces because of complicated tool path and uneven material removal. To achieve required profile tool path should be optimized. The work presented in this paper focuses on optimization of machining parameters leading to the development of precise aspheric lenses made of polycarbonate by precise machining.

\section{DESIGN OF SPDT EXERCISE}

In ultra-precision diamond turning, the quality of a surface plays an essential role in the functional performance of a product, especially in optical applications [4]. The quality of machined surface is affected by a number of factors, which include tool geometry, feed rate, material properties, spindle speed and tool \& work piece vibrations [5]. A better surface generation is of prime importance for the further development of ultra-precision machining technology and for better designs of machines to meet the needs for higher precision in future.

The main objective of this study is to find out which set of machining parameters can be used or adapted to improve the precision machining process as a finishing process for polycarbonate lenses. To investigate this, the problem is split in to two parts: 1) A number of machining cuts are conducted on polycarbonate disc with different machining parametric combinations. 2) In second part, series of compensation cycles are attempted to optimize the tool path to remove the profile error from polycarbonate lenses. 
All these machining experiments are performed at the National Aspheric Facility, Central Scientific Instrument Organization (CSIR-CSIO), Chandigarh, India. This Facility is equipped with Nanoform-250 (Taylor Hobson make) a 2axis SPDT equipment for precision machining and PGI-120 Talysurf (Taylor Hobson make) contact profiler and Coherence Correlation Interferometer (CCI-6000, Taylor Hobson make) for surface characterization.

\section{PARAMETERS FOR OPTIMIZATION}

A splendid surface roughness can only be achieved by proper combination of process parameters. Factors which affect the surface quality are differentiated into two major types, controllable and uncontrollable parameters [6]. Machine tool vibration, ambience and metrology practice are considered to be the uncontrollable parameters, while cutting speed, feed rate, tool nose radius, coolant, depth of cut are considered to be the controllable parameters. We may be able handle the uncontrollable parameters effectively, but one has to carefully selecting the best machining combination, failure of which would result in very rough surfaces. Thus the greatest challenge lies in one selecting the optimum combination of the process parameters to get the best surface quality. The parameters chosen for optimization are as: Spindle speed (SS), Feed rate (TFR), Depth of cut (DoC).

\section{EXPERIMENTATION}

A large number of theoretical and experimental studies on surface roughness of machined products have been reviewed, wherein cutting conditions such as cutting speed, feed rate, depth of cut, tool geometry and material properties of both tool and work piece significantly influence surface finish of the machined parts. From the published work, it is observed that there many additional factors which affect the surface quality. Thus the choice of optimized parameters becomes very important to control the required surface quality. The aim of this work is to investigate the individual and comprehensive effect of process parameters on surface roughness and optimising for the best combination of the parameters for the same.

For current study machining parameters selected are: Spindle Speed (1000rpm, 2000rpm, and 3000rpm), Feed Rate $(1 \mu \mathrm{m} / \mathrm{rev}, 3 \mu \mathrm{m} / \mathrm{rev}$, and $6 \mu \mathrm{m} / \mathrm{rev})$ and Depths of Cut $(2 \mu \mathrm{m} / \mathrm{rev}, 5 \mu \mathrm{m} / \mathrm{rev}$, and $10 \mu \mathrm{m} / \mathrm{rev})$. A diamond tool (Contour-make) with nose radius $1 \mathrm{~mm}$ is used for study with geometry: rack angle: $0^{\circ} \mathrm{C}$, front clearance: $10^{\circ} \mathrm{C}$, tool nose waviness: $2 \mu \mathrm{m}$ and shank dimensions: $6.35 \times 6.35 \times 51 \mathrm{~mm}$. A series of polycarbonate discs of diameter $35 \mathrm{~mm}$ and $10 \mathrm{~mm}$ thick are held by a vacuum chuck for strain free holding, while machining. The tests are conducted with constant cooling conditions throughout. Vacuum based chip extractor is used to remove the chips. Each polycarbonate disc is characterized off-line post SPDT. The surface roughness and peak to valley waviness are measured by using a mechanical profiler for $28 \mathrm{~mm}$ scan of all machined samples. Above machining parametric exploratory effort may provide with the optimum machining parametric matrix. But this is not sufficient to generate desired aspheric profile, and an optimized tool path is required. For this, a series of compensation cycles are performed on rough aspheric surface.

\section{ANALYSIS}

This study focuses on the influence of machining cutting parameters (in selected ranges) on the surface quality of the polycarbonate material during SPDT. Total 27 SPDT operations are conducted: 3 Spindle Speeds x 3 Tool Feed Rates x 3 Depths of Cut. Nearly uniform thermal conditions $\left(20-25^{\circ} \mathrm{C}\right)$ are maintained during SPDT \& and surface metrology. To investigate the effects of machining parameters all metrology values for roughness ( $\mathrm{Ra}$ ) and peak to valley $(\mathrm{Pt})$ are plotted in graphs with respect of different machining parameters. Figures 1-3 show the relation of surface quality with different machining parameters for depth of cut $2 \mu \mathrm{m}$, $5 \mu \mathrm{m}$ and $10 \mu \mathrm{m}$ respectively.

\subsection{Tool Path Optimization}

To analyze the method of tool path compensation, an aspheric surface is generated as per above machine parametric study. Compensation routine (Fig.4) has been applied to the machined surfaces to achieve the minimum residual error.

The tool path compensation cycle starts with the definition of desired aspheric surface by the conic equation:

$$
\mathrm{Z}=\left(\mathrm{c} \mathrm{r}^{2}\right) /\left\{1+\sqrt{ }\left[1-(1+\mathrm{k}) \mathrm{c}^{2} \mathrm{r}^{2}\right]\right\}+\sum \mathrm{a}_{\mathrm{i}} \mathrm{r}^{2 \mathrm{i}}
$$

Where, $c$ is the base curvature $(1 / \mathrm{R})$ at lens vertex; $k$ the conic constant; $r$ radial coordinate measured perpendicularly from the optical axis and $a_{i} r^{2 i}$ are higher order aspheric terms. The aspheric surface studied has Radius of Curvature: $44.5164 \mathrm{~mm}$ (Convex), Clear Aperture: 48mm, Conic constant: 1.30227, Sag: $6.333346 \mathrm{~mm}$, Lens diameter: $52 \mathrm{~mm}$.

DIFFSYS software is used to generated the tool path for the aspheric surface generation in terms of semi clear aperture ( $x$ values of work-piece movement) vs. sag ( $\mathrm{z}$ values of tool movement).

These sag table values are then provided to SPDT equipment to generate aspheric surface, which is then characterised on a Form Talysurf profilometer. The raw scanned (SPDT) surface data is exported for aspheric analysis, which in comparison with the intended aspheric profile generates the aspheric profile error. This profile is further exported to DIFFSYS. Then the profile error is incorporated in the previous tool path to generate a new compensated tool path. This compensated tool path is once again loaded into the SPDT equipment for re-machining, followed by re-characterization of surface. The iterative process is repeated till the desired profile is achieved. 

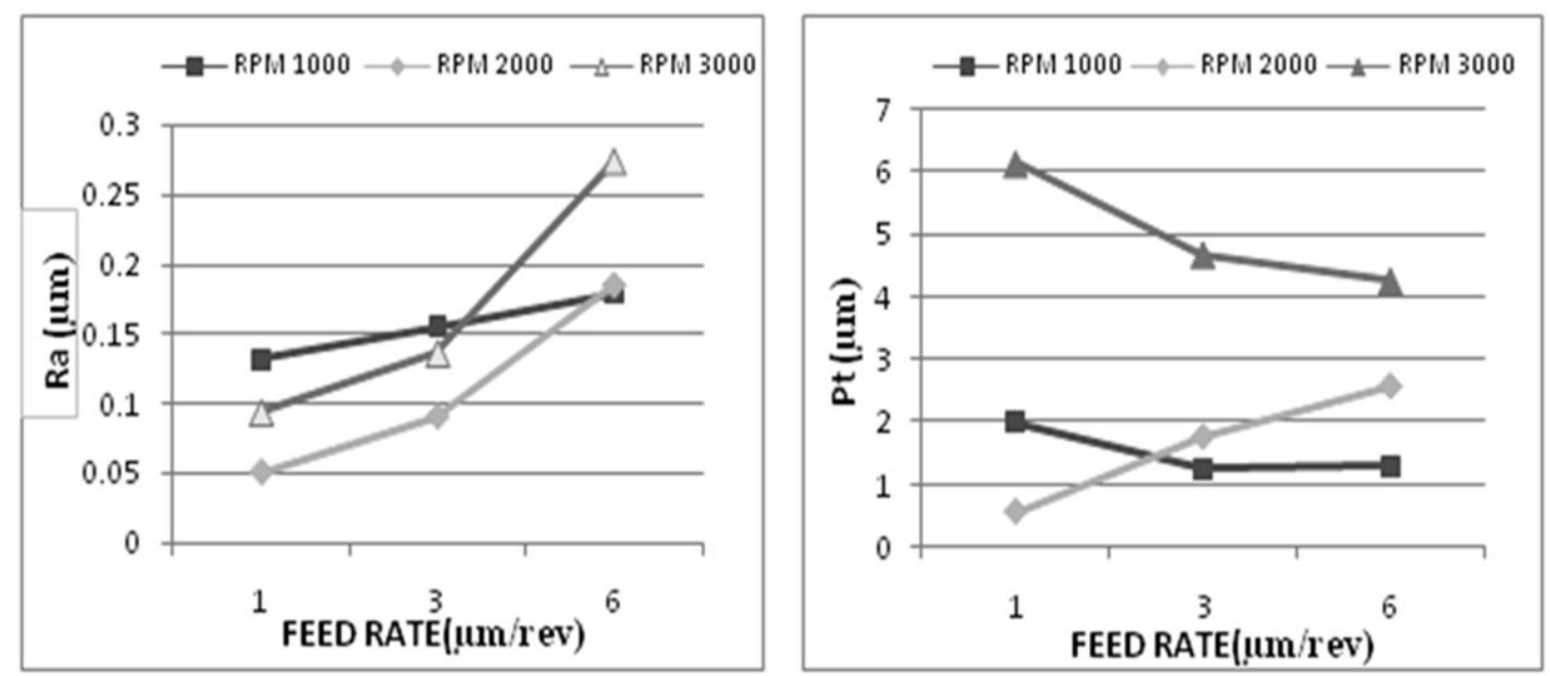

Fig.1: Surface quality $v s$. SPDT machining parameters (Depth of Cut: $2 \mu \mathrm{m}$ )
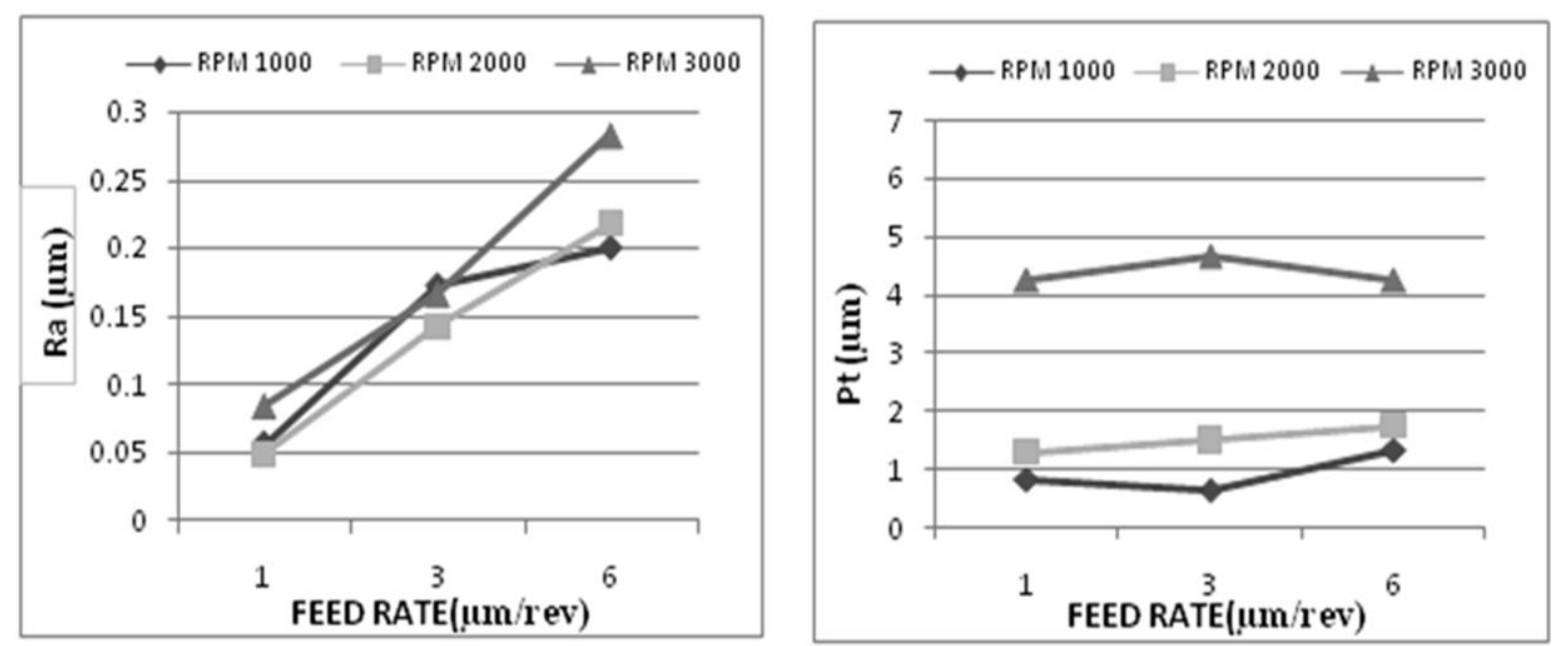

Fig.2: Surface quality vs. SPDT machining parameters (Depth of Cut: 5um)
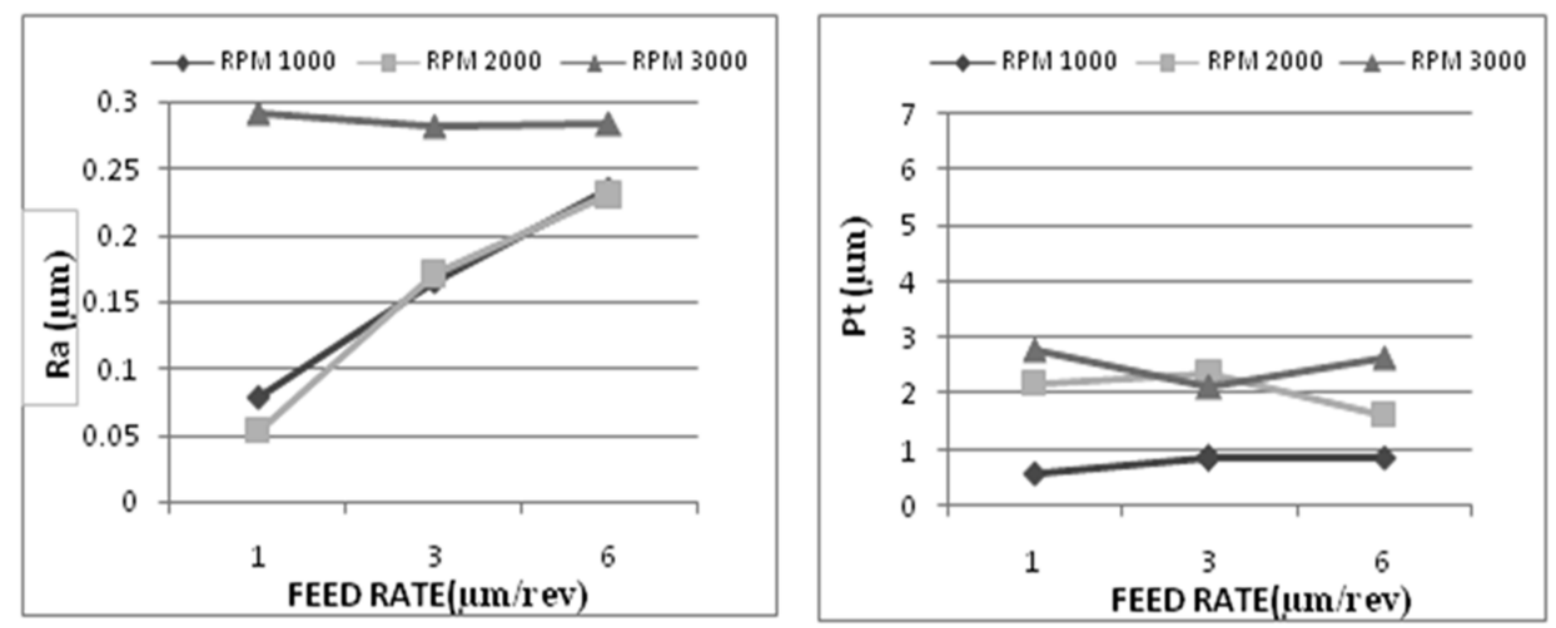

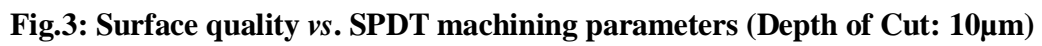




\section{RESULTS AND DISCUSSION}

The aim of this study is to investigate the effect of process parameters on surface quality $\&$ to optimize the tool path. The influence of spindle rotational speed is investigated for polycarbonate. For this, SPDT exercises are conducted with different cutting speeds and it is observed that an increase in cutting speed would result in rise in temperature at the primary shear zone. Since a constant rotational speed is applied, the cutting speed at the center of work piece equals nearly zero. Evaluation of the surface roughness is performed from nearly the center of the work piece to its outer diameter. An effect of spindle speed on surface roughness is shown in Fig.5.

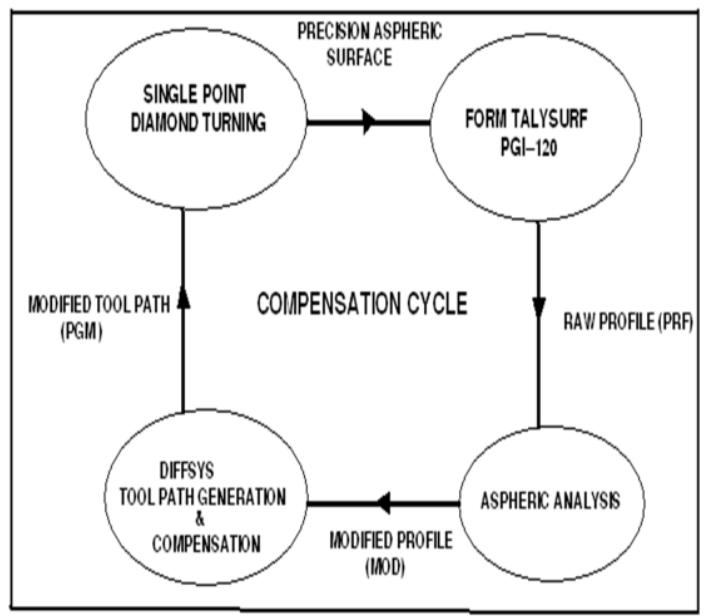

Fig.4: Tool path compensation cycle for aspheric surface

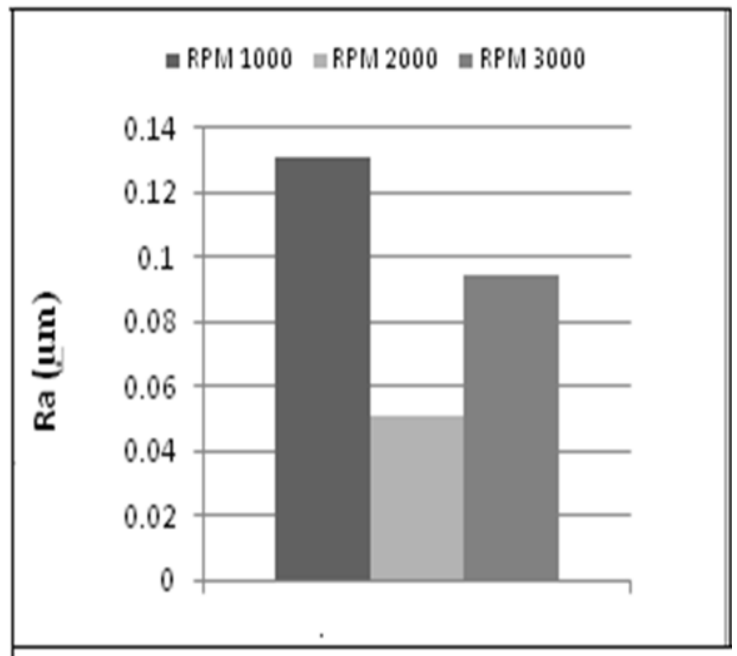

Fig.5: Effect of Spindle Speed on surface roughness (DoC: $2 \mu \mathrm{m} \&$ Feed rate: $1 \mu \mathrm{m} / \mathrm{rev}$ )

Surface finish produced during the diamond turning operation is mainly due to the combined effects of tool feed rate and tool geometry. Movement of a cutting tool across the surface of the work-piece component produces a finished surface, while leaving notable tool marks behind. The theoretical surface finish is given as:

$$
\mathrm{Ra}=\mathrm{F}^{2} / 8 \mathrm{R}
$$

Where $\mathrm{F}$ is feed rate and $\mathrm{R}$ is tool nose radius. Figure 6shows the effect of tool feed rate on surface finish for polycarbonate with spindle speed 2000rpm and depth of cut $2 \mu \mathrm{m}$. It is seen that a decrease in depth of cut results in reduced peak to valley error but does not have considerable effect on roughness. However, during machine operation, it is observed that increase in depth of cut causes rise in temperature at cutting zones. Flow of chips changed with increased temperature, which greatly affects transparency of polycarbonate discs.

Figures 7 and 8 show the effect of depth of cut on roughness and Pt respectively for polycarbonate while machining with spindle speed 2000rpm and feed rate $1 \mu \mathrm{m} / \mathrm{rev}$.

It is observed that by modifying the tool path, profile error of aspheric surface is significantly reduced. The comparison between aspheric figure error, before and after tool path compensation is given in Table-1. Results of compensation cycles on aspheric profile can be clearly shown in Figs. 9-11.

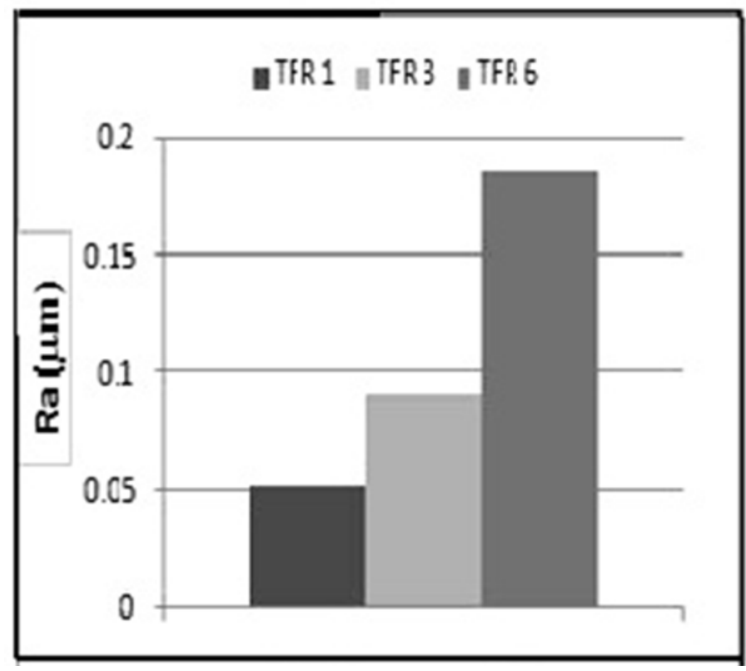

Fig. 6: Effect of tool feed rate on surface roughness

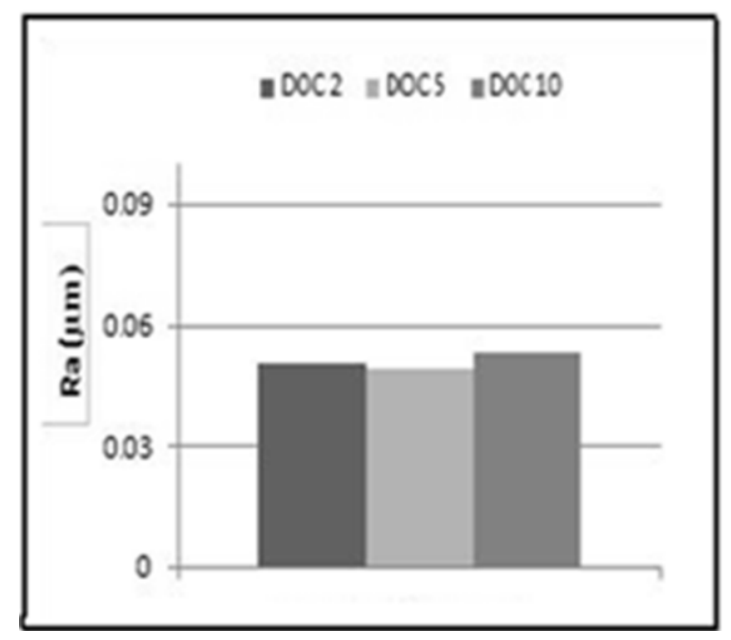

Fig.7: Effect of depth of cut on surface roughness 


\section{CONCLUSIONS}

The surface roughness and peak to valley errors in the diamond turning process have been measured for machining of polycarbonate under different cutting conditions. Based on the experimental results, the following conclusions are drawn:

1) Tool feed is the dominant parameter for surface roughness followed by the spindle rotational speed. Depth of cut shows minimal effect on surface roughness compared to other parameters.

2) Depth of cut is the leading parameter for peak to valley error, followed by spindle rotational speed. Feed rate does not have considerable effect on Pt.

3) Effect of depth of cut on Pt varies with spindle speed. However, for achieving good optical surface on the polycarbonate work piece, lower depth of cut is preferred.

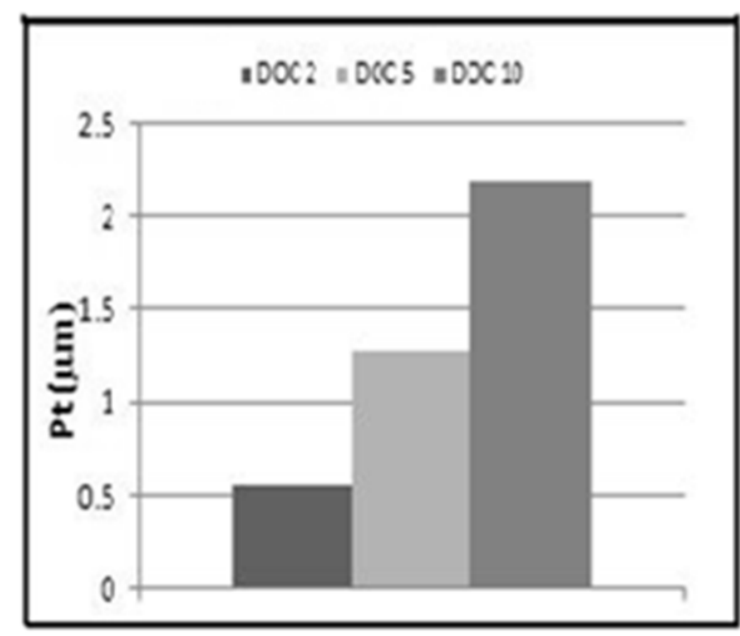

Fig.8: Effect of depth of cut (DoC) on Pt

Table 1- Results of compensation

\begin{tabular}{|c|c|c|}
\hline $\begin{array}{c}\text { Compensation } \\
\text { cycles }\end{array}$ & $\begin{array}{c}\text { Figure } \\
\text { error(nm) }\end{array}$ & $\begin{array}{c}\text { Peak to } \\
\text { Valley error } \\
\mathrm{Pt}(\mu \mathrm{m})\end{array}$ \\
\hline $\begin{array}{c}\text { Before } \\
\text { Compensation }\end{array}$ & -2704.8 & 4.09 \\
\hline $\begin{array}{c}\text { After1st } \\
\text { Compensation }\end{array}$ & -1707.1 & 2.52 \\
\hline $\begin{array}{c}\text { After 2 } \\
\text { Compensation }\end{array}$ & -18.32 & 2.48 \\
\hline
\end{tabular}

4) Spindle rotational speed of 2000rpm, tool feed rate of $1 \mu \mathrm{m} / \mathrm{rev}$ and depth of cut of $2 \mu \mathrm{m}$ are selected for precise machining of polycarbonate.

5) The process of the optimization of tool path for aspheric and its effects on profile are demonstrated.

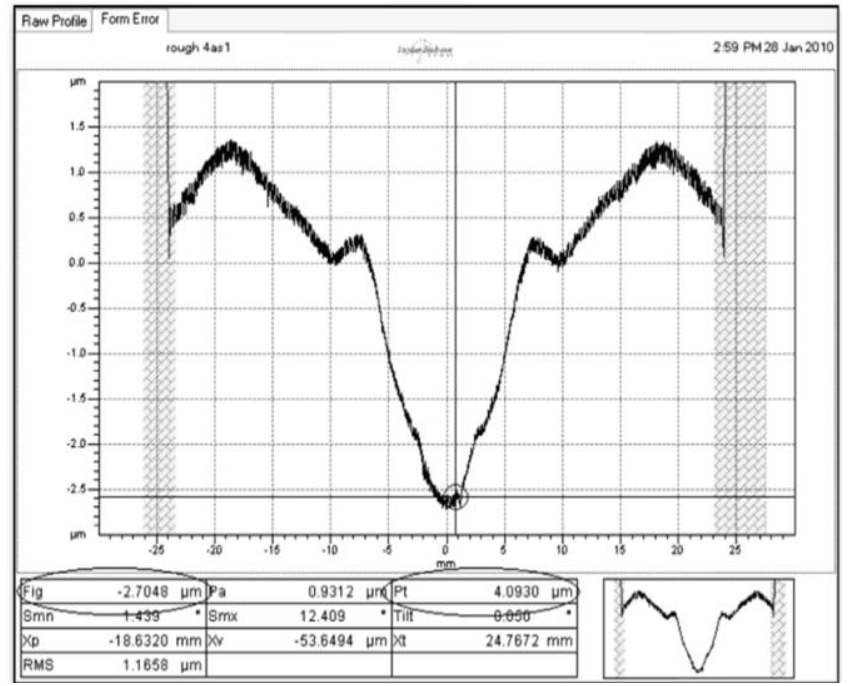

Fig.9: Aspheric lens figure error and peak to valley error (Pt) before compensation

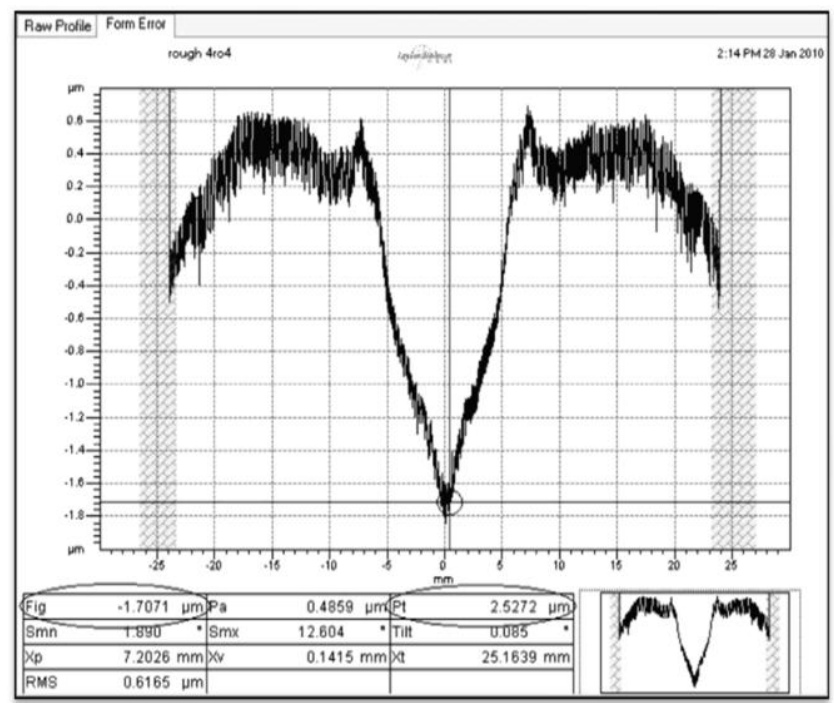

Fig.10: Aspheric lens figure error and peak to valley error (Pt) after $1^{\text {st }}$ compensation cycle

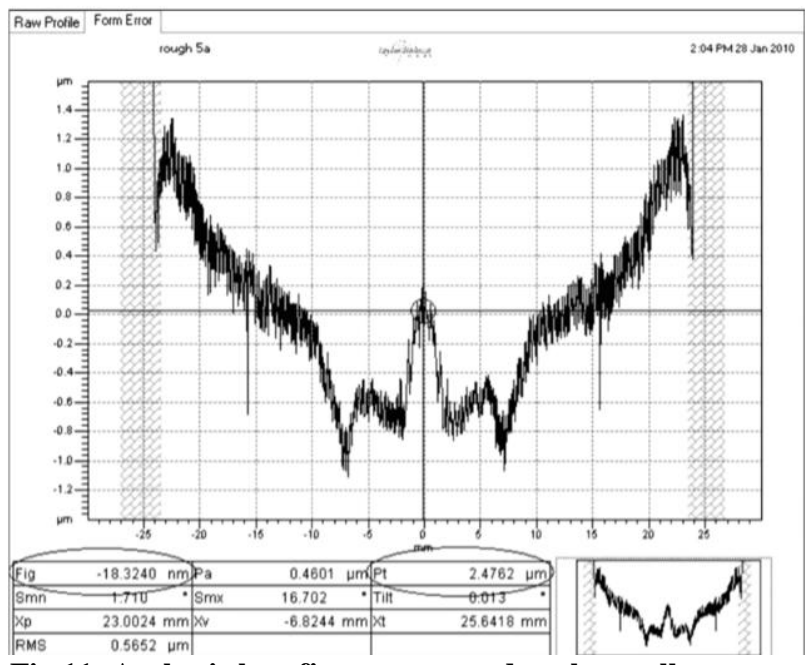

Fig.11: Aspheric lens figure error and peak to valley error (Pt) after $2^{\text {nd }}$ compensation cycle 


\section{REFERENCE}

[1] W.M.Chiu and W.B.Lee "Development of UltraPrecision Machining Technology “, Department of Manufacturing Engineering, The Hong Kong Polytechnic University, Hong Kong.

[2] T.T. Saito, "Diamond turning of optics: The past, the present and the exciting future", Opt. Eng., Vol. 17 (1978), 570-573.

[3] Gubbels, Guido P.H.'Diamond Turning of Glassy Polymers" Technische Universities Eindhoven, 2006.
[4] Saito, T.T., "Diamond turning of optics: The past, the present and the exciting future", Opt. Eng., Vol. 17 (1978), pp 570-573.

[5] Cheung C.F., Lee, W.B., (2006), "Characterizations of nanosurface generation in single-point diamond turning", Chinese Journal of Manufacturing Technology, Vol.41, pp 851-875.

[6] Iwona Piotrowska, Christina Brandt (2009), "Mathematical model of micro turning process", International Journal of Advanced Manufacturing Technology, Vol. 4, pp 80-89. 